Review

\title{
Ion-Selective Electrodes for Detection of Lead (II) in Drinking Water: A Mini-Review
}

\author{
Xiaochao Tang * (D), Po-Yen Wang and Gabrielle Buchter \\ Department of Civil Engineering, Widener University, Chester, PA 19013, USA; pwang1@widener.edu (P.-Y.W.); \\ gebuchter@widener.edu (G.B.) \\ * Correspondence: xtang@widener.edu; Tel.: +1-610-499-4046; Fax: +1-610-499-4461
}

Received: 23 May 2018; Accepted: 22 August 2018; Published: 24 August 2018

check for updates

\begin{abstract}
Despite the fact that the adverse health effects due to the intake of lead have been well studied and widely recognized, lead contamination in drinking water has been reoccurring worldwide, with some incidents escalating into a public drinking water crisis. As lead contamination is often related to lead-based pipes close to or inside homes, it is not realistic, at least in the near term, to remove and replace all lead connection pipes and lead-based plumbing. Effective monitoring of lead concentration at consumers' water taps remains critical for providing consumers with first-hand information and preventing potential wide-spread lead contamination in drinking water. This review paper examines the existing common technologies for laboratory testing and on-site measuring of lead concentrations. As the conventional analytical techniques for lead detection require using expensive instruments, as well as a high time for sample preparation and a skilled operator, an emphasis is placed on reviewing ion-selective electrode (ISE) technology due to its superior performance, low cost, ease of use, and its promising potential to be miniaturized and integrated into standalone sensing units. In a holistic way, this paper reviews and discusses the background, different types of ISEs are reviewed and discussed, namely liquid-contact ISEs and solid-contact ISEs. Along with the potential opportunities for further research, the limitations and unique challenges of ISEs for lead detection are also discussed in detail.
\end{abstract}

Keywords: ion selective electrode; heavy metals; potentiometric characterization; Nernstian response

\section{Background and Introduction}

Safe and clean drinking water is essential to public health and the prosperity of communities. Heavy metal lead contamination in drinking water is a health hazard. Infants and young children are particularly vulnerable to the adverse health effects of lead. Exposure to lead impairs children's physical and mental development, and even low levels of lead in the blood of children can cause a reduced intelligence quotient (IQ) and attention span, learning disabilities, and behavioral problems, among others. High lead levels may cause severe neurological problems such as coma, convulsions, and damage to kidneys [1]. Most source waters naturally have very low levels of lead and drinking water is generally free of lead as it leaves the treatment facility. The heavy metal is introduced into drinking water due to metal corrosion in the peripheral water distribution system, especially the service lines connecting the households to the main lines and lead-based plumbing within the households, particularly when the corrosion control treatment is not optimized [2,3]. The United States' Lead and Copper Rule (LCR), first promulgated in 1991, requires water systems to conduct tap water testing to determine levels of lead and copper [4]. An action threshold of 15 parts per billion (ppb) or $7.2 \times 10^{-8} \mathrm{M}$ has been established for public drinking water systems. The public drinking water system is out of compliance and certain remedial actions must be taken if more than 10 percent of a tested sample pool have tap water with a lead level higher than $15 \mathrm{ppb}$ or $7.2 \times 10^{-8} \mathrm{M}$. 
Despite the legally established action value of lead levels in drinking water, incidents with disastrous consequences have occurred repeatedly. Examples include lead contamination in drinking water in Washington D.C. from 2001 to 2004, and more recently, the lead contaminated water in Flint, Michigan, which led to a declaration of a state of emergency by the federal government [5-7]. The current law in the United States requires public water suppliers to collect water samples at consumers' taps from high-risk households. The water samples are typically then sent to a certified laboratory to be tested for lead levels. However, according to the law, only a fraction of the homes are screened for potential elevated lead levels. For example, as an older city where lead-based pluming and lead service lines are more likely to be present, the city of Philadelphia in the state of Pennsylvania only had to test about 100 homes every three years to meet the standard [8]. The current rule has a loophole that allows the water systems to implement their sampling procedures to intentionally avoid exceeding the action level [9]. Furthermore, the recurrence of the aforementioned water crisis due to lead contamination indicates that the current rule and its associated common practice of lead level monitoring has limited effectiveness in protecting the public health from lead contamination.

Recognizing the complexity and significant challenges in the implementation of the current Lead and Copper Rule, a recently-released white paper by the United States Environmental Protection Agency (U.S. EPA) on revising the rule has recommended proactive full lead service line replacement to eliminate one of the primary sources of lead in drinking water [9]. However, the white paper also points out that the burden of cost ( $\$ 2500$ to $\$ 8000$ or higher per line) on consumers to replace a lead service line can be prohibitive, particularly given that lead service lines are often located in economically disadvantaged communities. This suggests that, until the lead service lines and lead-based pluming are replaced, effectively and reliably monitoring the lead levels in drinking water would still be the primary approach to safeguard the public from lead exposure through drinking water.

In European Union (EU) countries, lead pipes are also common with an initial estimate that about $25 \%$ of dwellings in the EU have a lead pipe, which results in an estimate of 120 million people in the EU who are at potential risk from lead in their drinking water [10]. It is also estimated that about $65 \%$ of dwellings that have a lead pipe are likely to exceed the EU $10 \mathrm{mg} / \mathrm{L}$ standard, the legal requirement set in 2013. Removal of lead pipes has not been well received in EU countries because of the costs and disruption involved. It is suggested that the only comprehensive way to protect the public from lead contamination in drinking water is to reduce the plumbosolvency of the water supplies by using corrosion inhibitors such as optimized orthophosphate [11].

This paper reviews the current commonly used techniques to detect lead levels in drinking water, including laboratory tests using more sophisticated instruments and techniques that allow for on-site measurements. As continuous online monitoring at the consumers' taps offers an opportunity for the consumers to examine their drinking water lead levels first hand, particular emphasis is placed on reviewing the techniques based on ion selective electrodes (ISEs) that can be readily integrated with an electrochemical sensor for potential online monitoring of lead levels.

\section{Commonly-Used Laboratory Techniques for Measuring Lead Levels in Drinking Water}

To detect and determine a heavy metal trace in drinking water, first, water samples are collected on site after a minimum of $6 \mathrm{~h}$ of stagnation. The water samples are then transported to a certified central laboratory to be tested. There are currently a number of laboratory techniques based on atomic spectroscopy, by which the elemental composition of a heavy metal is determined, including atomic absorption spectroscopy (AAS), atomic emission spectroscopy (AES), and X-ray fluorescence, inductively coupled plasma mass spectrometry (ICP-MS). AAS is based on the atomization of an aqueous sample in a flame or graphite furnace and the absorbance of light by the metal atoms in the sample. AAS only allows for analysis of one element at a time and solid samples must be digested to aqueous solution prior to analysis. AES uses high temperature plasma or flame to excite elements in an aqueous sample to an upper electronic state and observes the light emitted as it returns to the 
ground state. XRF involves using X-rays to cause excitation of inner shell electrons, which are excited to high energy levels before decaying down and releasing energy in the form of fluorescence [12].

The aforementioned laboratory techniques are sophisticated and offer excellent sensitivity and limit of detection (LOD) that can detect lead levels at lower part per billion (ppb) levels. In addition to the expensive, sophisticated, and often bulky instrumentation required, trained personnel are required to operate the instruments and perform the testing. These techniques are limited to laboratory testing on prepared water samples. Using these laboratory techniques for large-scale determination of heavy metals can be costly, time consuming, and labor intensive. Although there are field portable XRF instruments, they have high detection limits that not appropriate for trace-level detection.

\section{Techniques for Onsite and Discrete Measurements of Lead Levels}

In response to the growing demands of rapid detection and assessment of heavy metal contamination, particularly in the field of environment monitoring, great efforts have been expended to develop technologies and methods to allow for onsite and discrete measurements of heavy metals. There are three primary methods of onsite detection of heavy metals: a colorimetric method, a biosensor-based method, and an electrochemical method.

A colorimetric method is based on spectrophotometry and determines the presence and concentration of a chemical element or chemical compound in a solution with the aid of a color reagent. Depending on the level of accuracy required, colorimetric results are analyzed using a spectrophotometer. For heavy metal detection, some widely used colorimetric methods include arsenic analysis using silver diethyldithiocarbamate, hexavalent chromium using diphenylcarbohydrazide, and copper analysis using bicinchoninate $[13,14]$. Matrix interferences in colorimetric methods either disrupt the reaction between the reagent and the analyte or interfere with the spectrometric light measurement.

Biosensors that are based on interfaces, such as microorganisms, enzymes, microspheres, and nanomaterials, have been developed to detect heavy metals $[15,16]$. Compared to traditional inorganic reagents, the more complex biological molecules allow for reagents with greater selectivity and less interference. Sensors with enzymes that can detect ppb levels of lead, uranium, copper, mercury, zinc, and cadmium have been developed [17-19]. In particular, DNA-based sensors have gained increasing attention due to the fact that some metal ions selectively bind to some bases to form stable metal-mediated DNA duplexes [20,21]. For lead $\left(\mathrm{Pb}^{2+}\right)$ detection, most sensors are based on the $\mathrm{Pb}^{2+}$-dependent DNAzyme and the $\mathrm{Pb}^{2+}$-stabilized G-quadruplex [22,23]. Based on DNAzyme and fluorescence, a commercial hand-held product has been developed to measure heavy metal concentration (AND1000 Fluorimeter, ANDalyze, Champaign, IL, USA) at the detection limit of $2 \mathrm{ppb}$ lead level [24].

As a branch of electrochemistry, the technique of voltammetry analyzes electroactive species, including heavy metals, by applying a potential to a system of electrodes and measuring the resulting currents flowing through the electrochemical cell. The electrical potential of the reactions and the magnitude of the current produced are used to determine the identity of the species and its concentration, respectively [25]. Traditionally, voltammetry has been a laboratory-based method, though in recent years, onsite voltammetry has become more prevalent as the size and cost of voltammetric equipment has been reduced. Typical methods for heavy metal detection include square-wave stripping voltammetry, differential-pulse stripping voltammetry, and linear-sweep stripping voltammetry. Micro, macro, and screen-printed electrodes have been used, consisting of a range of materials including glassy carbon, mercury, gold, silver, boron doped diamond, and platinum. Based on differential pulse anodic stripping voltammetry (ASV), the SA1100 Scanning Analyser by Palintest (Gateshead, UK) can detect lead levels in water with a limit of $2 \mathrm{ppb}$ [26]. Using cathodic stripping voltammetry (CSV), the PDV6000 Ultra by Modern Water (Guildford, UK) can detect multiple heavy metals at a single digital ppb level [27]. Common problems encountered in voltammetric analysis include high concentrations of one ion that can potentially mask the presence of 
other species and the presence of organic matter, like humic material, which binds with the metal ions and adsorb onto the electrode surface.

\section{Ion-Selective Electrode (ISE) Technology for Detecting Lead in Water}

Ion-selective electrodes (ISEs) are electrochemical sensors that convert the ionic signal into a measurable electronic signal, often electrical potential. As one type of potentiometric sensing, ISE typically requires the use of a reference electrode to electrochemically determine the concentration of target ions in a variety of chemical environments. ISEs have been attractive for detecting heavy metal traces because of their very low detection limits, good selectivity, wide dynamic range, low cost, and portability for in-situ measurements [28-30]. Many organic, inorganic, chelating, intercalating, and composite materials were studied as electroactive materials for the preparation of ion-selective membrane electrodes. Furthermore, the electrochemical detection used by ISE electrodes has a short analytical time, low power cost, high sensitivity, and easy adaptability for in-situ and online measurement. Electrochemical detection has become one of the most developed methods for continuous online monitoring of heavy metals. Modern electrochemical detection principles, coupled with recent advances in microelectronics and microfabrication, has led to powerful and compact analytical devices that can potentially be readily adopted for continuous and real-time monitoring of heavy metals [31,32]. In particular, applications of lab-on-a-chip (LOC) and microfluidics technologies have allowed for great improvements in compactness, reduction in fluid volume, and lower fabrication costs, among other advantages [33-35]. Furthermore, wireless communication technologies have allowed the development of a sensor network that enables more efficient online continuous monitoring of heavy metal based on electrochemical technologies [36]. Because of the aforementioned reasons, ISE electrode technologies hold a promising potential for online monitoring of trace lead levels in drinking water.

Based on the membrane material types, lead-selective ISEs can be categorized into three primary groups-polymeric membrane ISEs, polycrystalline membrane ISEs, and glass membrane ISEs-in which polymeric membrane ISEs are the most widespread type of lead-selective ISEs. As there are only a limited number of studies on lead-selective polycrystalline membrane ISEs and glass membrane ISEs, the focus of this review is placed on lead-selective polymeric ISEs created with different ionophore materials. Additionally, based on the contact type of the inner side of the membranes, ISEs can be categorized into liquid-contact ISEs and solid-contact ISEs. The following sections present and discuss in detail various types of lead-selective ISEs developed in liquid-contact and solid-contact forms.

\subsection{Liquid-Contact Ion-Selective Electrodes}

The conventional liquid-contact type ISE consists of a sensing membrane placed between two aqueous solutions, one being the sample and the other being the internal electrolyte. A common type of conductive sensing membrane is made of a plasticized polymeric phase, typically with poly(vinyl chloride) as a polymeric matrix, lipophilic ion-exchanger sites, and a lipophilic or covalently immobilized ionophore. The ionophore providing selectivity to a certain ion is embedded in the polymeric matrix. There are a variety of ISEs for lead detection that have been developed with different materials as ionophores. The performance of the ISEs varies in terms of their selectivity, sensitivity, limit of detection (LOD), and durability. As they are a large number of lead-selective ionophores, the primary groups of those chemical compounds include amides, thioamides, crown ethers, and calixarenes [37,38]. An oxy-diamides ISE electrode developed in early years showed lead (II) selectivity for $\mathrm{Li}^{+}, \mathrm{Ca}^{2+}, \mathrm{Mn}^{2+}, \mathrm{Zn}^{2+}, \mathrm{Mg}^{2+}$, and $\mathrm{Cu}^{2+}$ [39]. Another oxy-diamides group ISE was developed for lead (II) selectivity over sodium, potassium, and magnesium [40]. A tertiary amide showed near-Nernstian responses for divalent cations but poor selectivity towards lead (II) over potassium and sodium [41]. In general, amide derivatives exhibit higher stability constants than the thioamide derivatives while thioamides have a superior selectivity. 
Crown ethers represent another group of compounds that are commonly reported to be used as ionophores for ion-selective electrodes. Lipophilic lariat crown ethers have been found to act as lead-selective neutral carriers in liquid-contact membranes and show high selectivity over other heavy metal ions with low detection limits ranging between $10^{-6}$ and $10^{-7} \mathrm{M}$ [42]. Diaza-crown derivatives and aza-crown ethers have also been studied as an ionophore for lead (II) and their performance was found to be affected by the type of plasticizers and the presence of lipophilic salt [43,44]. Overall, for lead (II) detection, thioamide-derivatized calix arene is the most appropriate host molecule due to its excellent selectivity [45].

The aforementioned various types of lead-selective polymeric ISEs are summarized in Table 1 with respect to their ionophore materials used for the sensing membranes. The lead-selective polymeric ISEs' analytical characteristics, such as linear range, limit of detection, and durability, that are important for lead(II) detection are presented in Table 1. As can be seen in Table 1, the detection limit of polymeric ISEs could reach the requirement of the current EPA action level for lead(II) in drinking water (15 ppb). Table 1 also shows that the durability of the sensors ranges from several days to 15 months.

Table 1. Various types of lead-selective polymeric ISEs.

\begin{tabular}{|c|c|c|c|c|}
\hline Major Materials & $\begin{array}{l}\text { Linear Response } \\
\text { Range (M) }\end{array}$ & $\begin{array}{c}\text { Limit of } \\
\text { Detection (M) }\end{array}$ & Durability & References \\
\hline $\begin{array}{l}\text { Lipophilic oxa- and dioxadicarboxylic } \\
\text { amides }\end{array}$ & $10^{-2}$ to $10^{-5}$ & - & - & [39] \\
\hline $\begin{array}{c}\text { Lipophilic acyclic dibenzopolyether } \\
\text { diamides }\end{array}$ & $10^{-2}$ to $10^{-7}$ & - & 3 months & [41] \\
\hline Dithiophenediazacrown ether derivatives & $10^{-2.7}$ to $10^{-5}$ & $10^{-5.7}$ & & [43] \\
\hline $\begin{array}{l}\text { 4,7,13,16-tetrathenoyl-1,10-dioxa- } \\
\text { 4,7,13,16-tetraazacyclooctadecane }\end{array}$ & $10^{-3}$ to $10^{-5.3}$ & $10^{-5.7}$ & & [44] \\
\hline Calix[4]arenes & $10^{-2}$ to $10^{-6}$ & $10^{-6.5}$ & 6 weeks & [45] \\
\hline Naphthalene-sulfonamide derivative & $10^{-1}$ to $10^{-7}$ & $5.62 \times 10^{-8}$ & 4 months & [46] \\
\hline Ionophore $\mathrm{Pb}$ IV and NaTFPB & $10^{-3}$ to $10^{-8}$ & $1.20 \times 10^{-9}$ & Several days & [47] \\
\hline $\begin{array}{l}\text { Reduced graphene oxide/Gold } \\
\text { nanoparticle }\end{array}$ & - & $10^{-8}$ & - & [48] \\
\hline $\begin{array}{l}\text { Multi-walled carbon nanotubes and } \\
\text { nanosilica }\end{array}$ & $10^{-2}$ to $10^{-7}$ & $7.3 \times 10^{-8}$ & $>2$ months & [49] \\
\hline $\begin{array}{c}\text { Tetraphenylborate-Copolyaniline } \\
\text { nanoparticles }\end{array}$ & $10^{-3}$ to $10^{-10}$ & $2.2 \times 10^{-11}$ & 15 months & [50] \\
\hline
\end{tabular}

The lower limit of detection (LOD) is critical for ISEs to be used for detecting trace levels of heavy metal ions. The discovery and understanding of sample contamination due to various chemical processes by which some of the internal analyte ions leach out into the aqueous phase has contributed to significantly lowering the limit of detection [51,52]. It was found that a careful design of the internal solution, such as altering the composition of the inner electrolyte solution or simply diluting the inner electrolyte, can minimize the analyte ion flux from the membrane into the sample, and thus substantially lowering the limit of detection $[53,54]$. It is possible to achieve a picomolar level detection of lead (II) when internal electrolytes contain a chelator such as ethylenediaminetetraacetic acid (EDTA) and a significant concentration of an interferent such as sodium [55]. With an optimized internal solution in conjunction with improved conditioning and measuring protocols, a LOD of $3 \times 10^{-9} \mathrm{M}$ or $0.7 \mathrm{ppb}$ has been reported for polymeric membrane electrodes in real world drinking water samples [56]. In addition to optimizing the internal filling solution, other measures, such as increasing membrane thickness, decreasing the aqueous diffusion layer, the diffusion coefficient, and the amount of ion exchanger in the membrane, may also lead to lowering the detection limits [57]. As the lower detection limit for most techniques is either determined by the interferences or by the physical limitations of the instruments, the ultimate low detection limit of potentiometric ISE is still not yet known or fully understood [58]. 


\subsection{Solid-Contact Ion-Selective Electrodes}

Use of internal liquid filling solutions for the conventional liquid-contact ISEs limits their portability and creates the inherent limitation of the LOD due to transmembrane ion fluxes and sample contamination. Performance of liquid-contact ISEs may also be affected by evaporation of the internal solution and variations in sample temperature and pressure, which requires regular maintenance and care. Solid-contact ion-selective electrodes (SC-ISEs), on the other hand, eliminate the use of an internal liquid filling and are expected to be more portable and rugged. The two most common SC-ISEs are based on electroactive conducting polymers and high-surface area nanostructured materials, respectively. The first solid-contact (SC) electrode was developed using a silicone rubber membrane impregnated with copper (I) in 1970 for copper (II) with a satisfactory Nernst response in the range of $10^{-1}$ to $10^{-7} \mathrm{M}$ [59]. Subsequently, in 1971, the more well-known coated-wire ion-selective electrodes were developed with an electroactive species incorporated in a thin polymeric film coated directly onto a metallic conductor [60]. The coated-wire ISEs, however, have a major drawback of potential instability due to the capacitance formed between the electronic conductor and the ion-selective membrane [61].

By adding an intermediate layer, such as a hydrogel or electroactive conducting polymer, the performance of solid-contact ISEs (SC-ISEs) can be greatly improved. In particular, using an electroactive conducting polymer as the ion-to-electron transducer in conjunction with carrier-based ion-selective membrane has been extensively investigated for solid-contact ion-selective electrodes (SC-ISEs) [61-64]. Electroactive conducting polymers have been commonly used for SC-ISEs because of their ability to generate a high redox capacitance that leads to a high stability of the signal. Conducting polymers that have been extensively investigated for their applications in SC-ISEs include poly (pyrrole) [63], poly(aniline) [65], poly(3-octylthiophene) (POT) [66] and poly(3,4-ethylenedioxythiophene doped with poly(styrenesulfonate) (PEDOT (PSS)) [67]. A limit of detection (LOD) of $5.62 \times 10^{-8} \mathrm{M}$ has been achieved for lead (II) detection with a naphthalene-sulfonamide (NS) derivative as the ionophore modified with PEDOT (PSS) [46]. Using screen printing techniques, a disposable SC-ISE for lead (II) detection in environmental water has been developed and has shown good correlation with measurements by inductively coupled plasma mass spectrometry (ICP-MS) [47].

As stability and reproducibility of the conducting polymer-based SC-ISE measurements remain a challenge [68], in addition to optimizing the solid contact material and materials, novel approaches have recently been proposed to improve the stability of the signal and measurements. Without using an instrument, short-circuiting the conducting polymer-based SC-ISEs with a conventional reference electrode leads to a balance of potential between the SC-ISEs and the reference electrode, and eventually improvement of the stability and reproducibility $[69,70]$. Based on constant potential coulometry, a linear relation was observed between the logarithm of the sample ion change and the measured charge [71]. Although the internal solution and its associated ion flux issue is eliminated in SC-ISEs, SC-ISEs exhibit similar detection limits as the conventional liquid-contact ISEs likely due to contaminations caused by the polymeric membranes themselves [72]. It is expected that further optimization of the solid contact and ion-selective membrane will enhance the performance of polymer-based SC-ISE [73].

Along with electroactive conducting polymers, nanostructured materials with a high surface area is the other most commonly used and investigated ion-to-electron solid contact for SC-ISEs. These nanostructured materials include three-dimensionally ordered macroporous carbon [74], carbon nanotubes [75], and reduced graphene [76]. Because of their high surface-to-volume ratio and inert nature, these carbon-based nanostructured materials show long-term potential stability and are insensitive to light and $\mathrm{O}_{2}$. More importantly, unlike the conducting polymer-based SC-ISEs, carbon nanomaterials tend to be hydrophobic, thus preventing a water layer from being formed at the interface between the polymeric membrane and the network of nanomaterials, which also contributes to the stability of potentiometric measurements [77]. 
In addition to the more commonly-used electroactive conducting polymers and nanostructured materials, crystalline materials and chalcogenide glass (ChG) have been used for lead-selective solid-contact ISEs. Crystalline ISE membranes are generally made of polycrystalline or monocrystalline materials, with most of them comprising mixed crystals of low-soluble silver salts $\left(\mathrm{Ag}_{2} \mathrm{~S}\right)$ and heavy metal sulfides. Few studies were found using polycrystalline materials for lead-selective ISEs. A polycrystalline electrode comprising silver sulphide/lead sulphide $\left(\mathrm{Ag}_{2} \mathrm{~S} / \mathrm{PbS}\right)$ with a 1:1 molar ratio was reported to achieve a limit of detection of $1 \times 10^{-4} \mathrm{M}$ for lead(II) [78].

Compared to polycrystalline ISEs, ChG glass membranes have the advantages of high selectivity, excellent lifetime, and good chemical durability, although the fabrication of ChG glass electrodes often requires using an expensive technique such as pulsed laser deposition (PLD) [79,80]. Different chalcogenide glass systems (e.g., $\mathrm{GeSe}_{2}-\mathrm{PbSe}-\mathrm{PbTe}, \mathrm{PbS}-\mathrm{AgI}-\mathrm{As}_{2} \mathrm{~S}_{3}$, and $\mathrm{Pb}$-Ag-As-I-S) have been investigated as ISE membrane materials and were found to achieve a limit of detection as low as $1 \times 10^{-7} \mathrm{M}$ [81-83]. Although polycrystalline and ChG glass materials are extremely useful in many other applications, development of these materials for ISEs was hindered due to the difficulties that lay in designing a glass composition and crystalline materials for a particular ion and the poor ionic conductivity of most crystalline compounds as sensing materials [79,84].

\subsection{Challenges of Using Ion-Selective Electrodes for Detection of Lead (II) in Drinking Water}

Although an ISE has the advantages of low cost, ease of use, and low maintenance compared to many other analytical techniques that require using sophisticated instruments, there are three primary limitations and constraints of ISEs that remain as challenges, namely interference from other ions, effects of ionic strength of the solution, and potential drift over a period of time. This section aims to discuss these three primary limitations in detail and the opportunities associated with them to potentially move the ISE techniques and applications forward. The unique challenges associated with detecting bound and particulate lead in drinking water are also discussed.

\subsubsection{Interference from Other Ions and the Selectivity Coefficient}

As ISE measurement is based on potentiometry, and therefore selectivity of the lead-ISE to interfering ions is vital for ensuring a reliable detection and quantification of the lead ion concentration. Unfortunately, ISEs are not completely ion-specific and are sensitive to some other interfering ions to various extents. The ability of an ISE electrode to distinguish the interfering ions from the primary ion can be expressed as the selectivity coefficient. If the primary ion $(A)$ and the interfering ion $(B)$ have the same charge and form strong complexes with the ISE membrane's ionophore $(L)$ of the same stoichiometry, the selectivity coefficient $\left(K_{A, B}^{\text {pot }}\right)$ is determined as follows [85]:

$$
K_{A, B}^{p o t}=K_{A, B}, \frac{\beta_{B L}}{\beta_{A L}}
$$

in which $K_{A, B}$ is the ion-exchange constant for the uncomplexed ions in the aqueous and membrane phases, and $\beta_{\mathrm{BL}}$ and $\beta_{\mathrm{AL}}$ are the overall formation constants or stability constants of the complexes in the membrane phase. The International Union of Pure and Applied Chemistry (IUPAC) recommended a fixed interference method and a separate solution method to determine selectivity coefficients [86] as factors, such as leaching, desorption, and possible ion-exchange of the primary ion from the membrane to aqueous sample, need to be eliminated to obtain the true or unbiased selectivity coefficient.

For lead(II) detection in drinking water or simple environmental water samples, potentially interfering ions, such as $\mathrm{Fe}^{2+}, \mathrm{Na}^{+}, \mathrm{Ca}^{2+}, \mathrm{Mg}^{2+}$, and $\mathrm{Cu}^{2+}$, should be investigated to determine the required selectivity coefficients to achieve an adequately low LOD to enable detecting the highest allowed lead concentration in drinking water. For example, an ISE based on the lead-selective ionophore 4-tert-butylcalix[4]arenetetrakis (thioacetic acid dimethylamide) found the selectivity coefficient logarithmic value, $\log \mathrm{K}_{A, B}^{\text {pot }}$ for $\mathrm{Na}^{+}, \mathrm{Ca}^{2+}, \mathrm{Mg}^{2+}$, and $\mathrm{Cu}^{2+}$ equals $-3.9,-6.6,-6.1$, and -2.1, 
respectively, indicating $\mathrm{Cu}^{2+}$ is a main interference in this case, perhaps due to the strong competition of copper with lead in the deposition at the electrode [51]. It is, however, possible to use a masking reagent, such as $\mathrm{KCN}$, to minimize or eliminate the interfering effects of $\mathrm{Cu}^{2+}$ as $\mathrm{KCN}$ forms a complex with $\mathrm{Cu}^{2+}$ while it does not interact with $\mathrm{Pb}^{2+}[87]$.

\subsubsection{Effects of Ionic Strength of Solution and Activity Coefficient}

Ionic strength is used to reflect the overall effect of all ions in a sample and is determined as the molar concentration multiplied by the square of the valence of all ions. As ISE measures the activity or effective concentration of ions in equilibrium at the membrane surface, it may be closely related to the total number of ions in dilute solutions. However, for solutions of higher concentrations or greater ionic strength, the mobility of ions may be decreased due to greater inter-ionic interactions between all ions in the solutions, causing relatively fewer ions in the vicinity of the membrane than in the bulk solution and consequently an underestimate of the target ion concentration in samples with a high concentration and/or a complex matrix with a greater ionic strength. The activity of ions measured at the ISE membrane (also known as the effective concentration) is essentially the number of ions taking part in a chemical reaction. The activity coefficient $(\gamma)$ of an ion can be determined as the ratio of the measured activity to the actual concentration of the solution or, for dilute solutions, can be theoretically calculated as the following based on the Debye-Hückel equation [88]:

$$
\log (\gamma)=-\frac{A z^{2} \sqrt{I}}{1+B a \sqrt{I}}
$$

where $I$ is the ionic strength of the solution, $a$ is the ionic radius and equals 0.45 nanometers for $\mathrm{Pb}^{2+}, z$ is the valence of the ion and equals 2 for $\mathrm{Pb}^{2+}$, and $\mathrm{A}$ and $\mathrm{B}$ are constants depending on temperature. As the ionic strength, $I$, increases, the activity coefficient, $\gamma$, decreases, leading to a greater discrepancy between the measured activity and the actual concentration. For a solution with ionic strength $I=0.0001 \mathrm{M} / \mathrm{L}$, the activity coefficient for $\mathrm{Pb}^{2+}$ is equal to 0.955 , representing a $5 \%$ error in concentration measurement.

When constructing a calibration curve for an ISE at a higher concentration or greater ionic strength, the line tends to curve away from linearity due to the aforementioned effects of ionic strength on activity coefficient. Furthermore, the ionic strength of the sample solutions may be higher than that of the standards due to the fact that the sample solutions may often contain additional ions. This could lead to an incompatibility between the calibration curve and the sample and errors in the interpolated results, i.e., the calibration of ISE might not be valid for water samples for different ranges of activity.

To mitigate the effects of the ionic strength of solutions, a comparable ionic strength can be applied to most drinking water samples. The ionic strength adjustment buffer (ISAB) can be used to provide a constant ionic strength of unknown samples. This can diminish the source of uncertainty in the measurements by setting activity coefficients and the diffusion potential at approximately constant values, and thus minimizing any errors due to differences in ionic strength between the samples and standards. However, it should be pointed out that keeping a constant ionic strength may shift the equilibrium of reactions according to equilibrium constants, resulting in the difficulty in maintaining the traceability of the free lead(II) concentration. Furthermore, unfortunately, there is a lack of a reference material (standard) for ISEs with $\mathrm{Pb}^{2+}$ and complex matrixes where the analytical results obtained by ISEs can be validated [37].

\subsubsection{Potential Drift over Time}

The electrode response gradually changes over a period of time. The primary cause of the drift of the potential is the ion flux leakage across the ISE sensing membranes. The rate and extent of drift may vary depending on factors such as types of ISE and reference electrodes, and the age and degree of contamination of the electrodes. Potential drift of the ISEs can be checked by a standard solution or 
overcome by frequently measuring one calibration solution in between sample measurements, then re-calibrating when the potential value has drifted beyond an acceptable level. Once the extent of drift is known, then it should be possible to find the optimum time of use or number of samples analyzed before a calibration is necessary. Additionally, there are mathematical models that have been developed to estimate the time-dependent potential drifts $[89,90]$.

\subsubsection{Detection of Bound and Particulate Lead in Drinking Water}

Finally, it should be pointed out, when using the traditional instruments, such as ICP-MS and ICP-AES for lead detection, water samples are typically acidified to $\mathrm{pH} 4$ to assess total lead rather than just free, uncomplexed lead. When the $\mathrm{pH}$ of the water solution is around 5 or higher, lead(II) cations may undergo a complexation reaction to various hydroxyl complexes, turning into various forms of the complex such as $\mathrm{PbOH}^{+}, \mathrm{Pb}(\mathrm{OH})_{2}, \mathrm{~Pb}(\mathrm{OH})_{3}{ }^{-}, \mathrm{Pb}_{2}(\mathrm{OH})^{3+}$, and $\mathrm{Pb}_{3}(\mathrm{OH})_{4}{ }^{2+}$. However, for drinking water content, the complexation might be negligible [91]. Furthermore, it has been shown that the toxicity of metals is related to the activity of the free form of metal ions and not to the total concentration of metals [92]. Nevertheless, as the ion-selective electrodes are only sensitive to free lead ions of the analyte and do not respond to various complexed species of the analyte, caution should be exercised when distinguishing the free and bound analyte species in the speciation analysis.

As lead contamination in drinking water tends to occur in homes with old lead service lines, particulate lead species may co-exist with free lead ions in the aged water service lines [93]. A number of studies have indicated that significant contributions of particulate-associated lead can be mobilized as a function of flow rate and turbulence in certain water chemistries [94-97]. Lead-selective ISE sensors are not capable of detecting particulate lead. When adjusting the ionic strength, the $\mathrm{pH}$ of the sample solution can also be lowered with the acidic buffer at the same time, converting all possible lead species to $\mathrm{Pb}$ (II) ions. In addition, it is possible to predict and quantify particulate lead in drinking water through developing a correlation model based on the dissolved lead, properties of water, and equilibrium chemistry [98].

\section{Conclusions}

Access to safe and clean drinking water is vital to the health of people and prosperity of a community. The current common practice of monitoring lead levels in drinking water has not been able to effectively rule out or eliminate lead poison of water consumers, exemplified by the recent drinking water crisis in Flint, Michigan. Monitoring techniques based on ion selective electrodes potentially enables wide-area monitoring of lead levels for a community and identification of contamination sources and the extent of contamination, and thus better prevents the disastrous consequences.

This paper reviewed the common techniques that are employed to detect lead (II) in drinking water at trace levels, including laboratory testing using sophisticated instruments and techniques for on-site testing. The review placed an emphasis on the ion-selective electrode (ISE) techniques as ISEs have the promising potential to be miniaturized and integrated into a stand-alone sensor unit. Both the conventional liquid-contact ISEs and the more recently-developed solid-contact ISE techniques are reviewed in this paper. The common ionophores for liquid-contact ISE membranes are identified and limitations of the liquid-contact ISE techniques are discussed. Sample contamination due to ion-fluxes through the ISE membrane remains a challenge for achieving a lower limit of detection, although carefully optimizing the internal solution can mitigate the problem.

As on-site real-time monitoring requires using more portable and rugged sensors, solid-contact ISEs eliminate the use of inner filling solutions and hold the potential to create sensors that are less sensitive to changes of temperatures and pressures. The two most common materials used as the ion-to-electron transducers for solid-contact ISEs are reviewed: electroactive conducting polymers and high-surface area nanostructured materials. An outstanding issue with the use of conducting polymers in SC-ISE is the stability and reproducibility of potentiometric measurements due a water layer formed between the conducting polymer and the ISE membrane. Nanostructured materials, on other hand, 
are more hydrophobic and inert, particularly for carbon-based nanomaterials, which leads to more stable potentiometric measurements.

As the field of ISEs is still actively investigated, it is important to raise the awareness of the limitations of the ISE technologies for lead(II) detection, particularly the three primary limitations discussed in this review paper. It is anticipated that the performance of ISEs will be greatly improved, along with the evolution of technologies and the understanding of response mechanisms of ISE, and more importantly, the multidisciplinary collaboration between synthetic organic chemistry and electrochemistry.

Author Contributions: Conceptualization, X.T. and P.-Y.W.; Literature Review, G.B.; Data Curation, P.-Y.W.; Original Draft Preparation, X.T.; Manuscript review and editing, P.-Y.W.

Funding: This research received no external funding.

Conflicts of Interest: The authors declare no conflict of interest.

\section{References}

1. U.S. Environmental Protection Agency (EPA). Basic Information about Lead in Drinking Water. Available online: https:/ / www.epa.gov/ground-water-and-drinking-water/basic-information-about-lead-drinkingwater (accessed on 30 March 2018).

2. Renner, R. Out of plumb: When water treatment causes lead contamination. Environ. Health Perspect. 2009, 117, A542-A547. [CrossRef] [PubMed]

3. Renner, R. Exposure on tap: Drinking water as an overlooked source of lead. Environ. Health Perspect. 2010, 118, A68-A72. [CrossRef] [PubMed]

4. U.S. Environmental Protection Agency. Safe drinking water act lead and copper rule (LCR). Fed. Regist. 1991, $56,26460-26564$.

5. Edwards, M.; Triantafyllidou, S.; Best, D. Elevated blood lead in young children due to lead-contaminated drinking water: Washington, DC, 2001-2004. Environ. Sci. Technol. 2009, 43, 1618-1623. [CrossRef] [PubMed]

6. Bellinger, D.C. Lead contamination in Flint-An abject failure to protect public health. N. Engl. J. Med. 2016, 374, 1101-1103. [CrossRef] [PubMed]

7. Hanna-Attisha, M.; LaChance, J.; Sadler, R.C.; Champney, S.A. Elevated blood lead levels in children associated with the Flint drinking water crisis: A spatial analysis of risk and public health response. Am. J. Public Health 2016, 106, 283-290. [CrossRef] [PubMed]

8. Philadelphia Water. 2015. Available online: http://www.phila.gov/water/PDF/LeadStandard_2015.pdf (accessed on 12 January 2017).

9. U.S. Environmental Protection Agency. Lead and Copper Rule Revisions White Paper; U.S. Environmental Protection Agency: Washington, DC, USA, 2016.

10. Hayes, C.R.; Skubala, N.D. Is there still a problem with lead in drinking water in the European Union? J. Water Health 2009, 7, 569-580. [CrossRef] [PubMed]

11. Hayes, C.R.; Hydes, O.D. UK Experience in the Monitoring and Control $\mathrm{f}$ Lead in Drinking Water. J. Water Health 2012, 10, 337-348. [CrossRef] [PubMed]

12. Gauglitz, G.; Vo-Dinh, T. Handbook of Spectroscopy; John Wiley \& Sons: Hoboken, NJ, USA, 2003.

13. Vuković, J.; Matsuoka, S.; Yoshimura, K.; Grdinić, V.; Jurišić Grubešić, R.; Županić, O. Simultaneous determination of traces of heavy metals by solid-phase spectrophotometry. Talanta 2007, 71, 2085-2091. [CrossRef] [PubMed]

14. Ruiz, N.L.; Ariza, M.; Olmos, A.M.; Vukovic, J.; Palma, A.J; Capitan-Vallvey, L.F. Handheld colorimeter for determination of heavy metal concentrations. J. Phys. Conf. Ser. 2011, 307, 1-6. [CrossRef]

15. Bhargavi, M.; Sethuraman, S.; Krishnan, U.M.; Rayappan, J.B.B. A review on detection of heavy metal ions in water-In electrochemical approach. Sens. Actuators B Chem. 2015, 213, 515-533.

16. Cui, L.; $\mathrm{Wu}, \mathrm{J} . ; \mathrm{Ju}, \mathrm{H}$. Electrochemical sensing of heavy metal ions with inorganic, organic and bio-materials. Biosens. Bioelectron. 2014, 63, 276-286. [CrossRef] [PubMed]

17. Liu, J.; Lu, Y. A colorimetric lead biosensor using DNAzyme-directed assembly of gold nanoparticles. J. Am. Chem. Soc. 2003, 125, 6642-6643. [CrossRef] [PubMed] 
18. Chang, I.H.; Tulock, J.J. Miniaturized lead sensor based on lead-specific DNAzyme in a nanocapillary interconnected microfluidic device. Environ. Sci. Technol. 2005, 29, 3756-3761. [CrossRef]

19. Long, F.; Zhu, A.; Shi, H.; Wang, H.; Liu, J. Rapid on-site/in situ detection of heavy metal ions in environmental water using a structure-switching DNA optical biosensor. Sci. Rep. 2013, 3, 1-7. [CrossRef] [PubMed]

20. Clever, G.H.; Kaul, C.; Carell, T. DNA-metal base Pairs. Angew. Chem. Int. Ed. 2007, 46, 6226-6236. [CrossRef] [PubMed]

21. Willner, I.; Zayats, M. Electronic aptamer-based sensors. Angew. Chem. Int. Ed. 2007, 46, 6408-6418. [CrossRef] [PubMed]

22. Xiao, Y.; Rowe, A.A.; Plaxco, K.W. Electrochemical detection of parts-perbillion lead via an electrode-bound DNAzyme assembly. J. Am. Chem. Soc. 2007, 129, 262-263. [CrossRef] [PubMed]

23. Li, T.; Dong, S.; Wang, E. A lead(II)-driven DNA molecular device for turn-on fluorescence detection of lead(II) ion with high selectivity and sensitivity. J. Am. Chem. Soc. 2010, 132, 13156-13157. [CrossRef] [PubMed]

24. ANDalyze. Available online: http://andalyze.com/products/fluorimeter/ (accessed on 15 January 2017).

25. Bard, A.J.; Faulkner, L.R. Electrochemical Methods: Fundamentals and Applications, 2nd ed.; John Wiley \& Sons: Hoboken, NJ, USA, 2001.

26. Palintest Water Analysis Technologies. Available online: http://www.palintest.com/en/support/researchinsight/lead-drinking-water-testing (accessed on 15 January 2017).

27. Modern Water. Available online: https://www.environmental-expert.com/products/model-pdv-6000ultra-portable-metal-monitor-310298 (accessed on 15 January 2017).

28. Tutulea-Anastasiu, M.D.; Wilson, D.; Valle, M.D.; Schreiner, C.M.; Cretescu, I. A Solid-Contact Ion Selective Electrode for Copper(II) Using a Succinimide Derivative as Ionophore. Sensors 2013, 13, 4367-4377. [CrossRef] [PubMed]

29. Alam, M. Studies on the Preparation and Analytical Applications of Various Metal Ion-Selective Membrane Electrodes Based on Polymeric, Inorganic and Composite Materials-A Review. J. Macromol. Sci. Part A 2008, $45,1084-1101$.

30. Gupta, V.K.; Ganjali, M.R.; Norouzi, P.; Khani, H.; Nayak, A.; Agarwal, S. Electrochemical Analysis of Some Toxic Metals by Ion-Selective Electrodes. J. Crit. Rev. Anal. Chem. 2011, 41, 282-313. [CrossRef] [PubMed]

31. Li, M.; Gou, H.; Al-Ogaidi, I.; Wu, N. Nanostructured Sensors for Detection of Heavy Metals: A Review. ACS Sustain. Chem. Eng. 2013, 1, 713-723. [CrossRef]

32. Hanrahan, G.; Patil, D.G.; Wang, J. Electrochemical sensors for environmental monitoring: Design, development and applications. J. Environ. Monit. 2004, 6, 657-664. [CrossRef] [PubMed]

33. Huang, Y.; Mason, A.J. Lab-on-CMOS integration of microfluidics and electrochemical sensors. Lab Chip 2013, 13, 3929-3934. [CrossRef] [PubMed]

34. Hwang, S.; LaFratta, C.N.; Agarwal, V.; Yu, X. CMOS microelectrode array for electrochemical lab-on-a-chip applications. IEEE Sens. J. 2009, 9, 609-614. [CrossRef]

35. Erkal, J.L.; Selimovic, A.; Gross, B.C.; Lockwood, S.Y. 3D printed microfluidic devices with integrated versatile and reusable electrodes. Lab Chip 2014, 14, 2023-2032. [CrossRef] [PubMed]

36. Economou, A. Recent developments in on-line electrochemical stripping analysis-An overview of the last 12 years. Anal. Chem. Acta 2010, 683, 38-51. [CrossRef] [PubMed]

37. Guziński, M.; Lisak, G.; Kupis, J.; Jasiński, A.; Bocheńska, M. Lead(II)-Selective Ionophores for Ion-Selective Electrodes: A Review. Anal. Chim. Acta 2013, 791, 1-12. [CrossRef] [PubMed]

38. Ceresa, A.; Pretsch, E. Determination of Formal Complex Formation Constants of Various Pb2 ${ }^{+}$Ionophores in the Sensor Membrane Phase. Anal. Chim. Acta 1999, 395, 41-52. [CrossRef]

39. Lindner, E.; Toth, E.; Pungor, E. Lead-selective neutral carrier based liquid membrane electrode. Anal. Chem. 1984, 56, 1127-1131. [CrossRef]

40. Malinowska, E. Lead-Selective Membrane Electrodes Based on Neutral Carriers. Part I. Acyclic Amides and Oxamides. Analyst 1990, 115, 1085-1087. [CrossRef]

41. Ohki, A.; Kim, J.S.; Suzuki, Y.; Hayashita, T.; Maeda, S. Lead-Selective Poly(vinyl chloride) Membrane Electrodes Based on Acyclic Dibenzopolyether Diamides. Talanta 1997, 44, 1131-1135. [CrossRef]

42. Hasse, W.; Ahlers, B.; Reinbold, J.; Cammann, K. PbOH+-selective membrane electrode based on crown ethers. Sens. Actuators B Chem. 1994, 19, 383-386. [CrossRef] 
43. Yang, X.; Kumar, N.; Chi, H.; Hibbert, D.B.; Alexander, P.W. Lead(II)-selective Membrane Electrodes Based on Dithiophenediazacrown Ether Derivatives. Electroanalysis 1997, 9, 549-553. [CrossRef]

44. Yang, X.; Kumar, N.; Hibbert, D.B.; Alexander, P.W. Lead(II)-Selective Membrane Electrodes Based on 4,7,13,16-Tetrathenoyl-1,10-dioxa-4,7,13,16-tetraazacyclooctadecane. Electroanalysis 1998, 10, 827-831. [CrossRef]

45. Malinowska, E.; Brzozka, Z.; Kasiura, K.; Egberink, R.J.M.; Reinhoudt, D.N. Lead Selective Electrodes Based on Thioamide Functionalized Calix[4] Arenes as Ionophores. Anal. Chim. Acta 1994, 298, 253-258. [CrossRef]

46. Kamal, A.; Tejpal, R.; Bhalla, V.; Kumar, M.; Mahajan, R.K. Selective and sensitive lead (II) solid-contact potentiometric sensor based on naphthalene-sulfonamide derivative. Int. J. Environ. Sci. Technol. 2015, 12, 2567-2578. [CrossRef]

47. Anastasova, S.; Radu, A.; Matzeu, M.; Zuliani, C.; Mattinen, U.; Bobacka, J.; Diamond, D. Disposable Solid-Contact Ion-Selective Electrodes for Environmental Monitoring of Lead with ppb Limit-of-Detection. Electrochim. Acta 2012, 73, 93-97. [CrossRef]

48. Zhou, G.; Chang, J.; Cui, S.; Pu, H.; Wen, Z.; Chen, J. Real-Time, Selective Detection of Pb2+ in Water Using a Reduced Graphene Oxide/Gold Nanoparticle Field-Effect Transistor Device. ACS Appl. Mater. Interfaces 2014, 6, 19235-19241. [CrossRef] [PubMed]

49. Ganjali, M.R.; Motakef-Kazami, N.; Faridbod, F.; Khoee, S.; Norouzi, P. Determination of Pb2+ ions by a Modified Carbon Paste Electrode Based on Multi-Walled Carbon Nanotubes (MWCNTs) and Nanosilica. J. Hazard. Mater. 2010, 173, 415-419. [CrossRef] [PubMed]

50. Li, X.G.; Feng, H.; Huang, M.R.; Gu, G.L.; Moloney, M.G. Ultrasensitive Pb(II) Potentiometric Sensor Based on Copolyaniline Nanoparticles in a Plasticizer-Free Membrane with a Long Lifetime. Anal. Chem. 2012, 84, 134-140. [CrossRef] [PubMed]

51. Bakker, E.; Bühlmann, P.; Pretsch, E. Polymer Membrane Ion-Selective Electrods-What are the Limits? Electroanalysis 1999, 11, 915-933. [CrossRef]

52. Mi, Y.; Mathison, S.; Goines, R.; Logue, A.; Bakker, E. Detection Limit of Polymeric Membrane Potentiometric Ion Sensors: How Can We Go Down to Trace Level? Anal. Chim. Acta 1999, 397, 103-111. [CrossRef]

53. Mathison, S.; Bakker, E. Effect of Transmembrane Electrolyte Diffusion on the Detection Limit of Carrier-Based Potentiometric Ion Sensors. Anal. Chem. 1998, 70, 303-309. [CrossRef]

54. Szigeti, Z.; Vigassy, T.; Bakker, E.; Pretsch, E. Approaches to Improving the Lower Detection limit of Polymeric Membrane Ion-Selective Electrodes. Electroanalysis 2006, 18, 1254-1265. [CrossRef] [PubMed]

55. Sokalski, T.; Ceresa, A.; Zwickl, T.; Pretsch, E. Large Improvement of the Lower Detection Limit of Ion-Selective Polymer Membrane Electrodes. J. Am. Chem. Soc. 1997, 119, 11347-11348. [CrossRef]

56. Ceresa, A.; Bakker, E.; Hattendorf, B.; Günther, D.; Pretsch, E. Potentiometric Polymeric Membrane Electrodes for Measurement of Environmental Samples at Trace Levels: New Requirements for Selectivities and Measuring Protocols, and Comparison with ICPMS. Anal. Chem. 2001, 73, 343-351. [CrossRef] [PubMed]

57. Radu, A.; Peper, S.; Bakker, E.; Diamonda, D. Guidelines for Improving the Lower Detection Limit of Ion-Selective Electrodes: A Systematic Approach. Electroanalysis 2007, 19, 144-154. [CrossRef]

58. Bakker, E.; Pretsch, E. The New Wave of Ion-Selective. Anal. Chem. 2002, 74, 420A-426A. [CrossRef] [PubMed]

59. Hirata, H.; Dato, K. Copper(I) Sulphide-Impregnated Silicone Rubber Membranes as Selective Electrodes for Copper(II) Ions. Talanta 1970, 17, 883-887. [CrossRef]

60. Cattrall, R.W.; Freiser, H. Coated Wire Ion-Selective Electrodes. Anal. Chem. 1971, 43, 1905-1906. [CrossRef]

61. Bobacka, J. Potential Stability of All-Solid-State Ion-Selective Electrodes Using Conducting Polymers as Ion-to-Electron Transducers. Anal. Chem. 1999, 71, 4932-4937. [CrossRef] [PubMed]

62. Oyama, N.; Hirokawa, T.; Yamaguchi, S.; Ushizawa, N.; Shimomura, T. Hydrogen Ion Selective Microelectrode Prepared by Modifying an Electrode with Polymers. Anal. Chem. 1987, 59, 258-262. [CrossRef]

63. Cadogan, A.; Gao, Z.; Lewenstam, A.; Ivaska, A.; Diamond, D. All-Solid-State Sodium-Selective Electrode Based on a Calixarene Ionophore in a Poly(vinyl chloride) Membrane with a Polypyrrole Solid Contact. Anal. Chem. 1992, 64, 2496-2501. [CrossRef]

64. Pandey, P.C.; Prakash, R. Polyindole Modified Potassium Ion-Sensor using Dibenzo-18-Crown-6 Mediated PVC Matrix Membrane. Sens. Actuators B Chem. 1998, 46, 61-65. [CrossRef]

65. Bobacka, J.; Lindfors, T.; McCarrick, M.; Ivaska, A.; Lewenstam, A. Single-piece all-solid-state ion-selective electrode. Anal. Chem. 1995, 67, 3819-3823. [CrossRef] 
66. Veder, J.P.; De Marco, R.; Patel, K.; Si, P.C.; Grygolowicz-Pawlak, E.; James, M.; Alam, M.T.; Sohail, M.; Lee, J.; Pretsch, E.; et al. Evidence for a Surface Confined Ion-to-Electron Transduction Reaction in Solid-Contact Ion-Selective Electrodes Based on Poly(3- octylthiophene). Anal. Chem. 2013, 85, 10495-10502. [CrossRef] [PubMed]

67. Bobacka, J.; McCarrick, M.; Lewenstam, A.; Ivaska, A. All Solid-State Poly(vinyl chloride) Membrane Ion-Selective Electrodes with Poly(3-Octylthiophene) Solid Internal Contact. Analyst 1994, 119, 1985-1991. [CrossRef]

68. Hu, J.; Stein, A.; Bühlmann, P. Rational Design of All-Solid-State Ion-Selective Electrodes and Reference Electrodes. Trends Anal. Chem. 2016, 76, 102-114. [CrossRef]

69. Vanamo, U.; Bobacka, J. Instrument-Free Control of the Standard Potential of Potentiometric Solid-Contact Ion-Selective Electrodes by Short-Circuiting with a Conventional Reference Eelectrode. Anal. Chem. 2014, 86, 10540-10545. [CrossRef] [PubMed]

70. Vanamo, U.; Bobacka, J. Electrochemical Control of the Standard Potential of Solid-Contact Ion-Selective Electrodes Having a Conducting Polymer as Ion-to-Electron Transducer. Electrochim. Acta 2014, 12, 316-321. [CrossRef]

71. Vanamo, U.; Hupa, E.; Yrjana, V.; Bobacka, J. New Signal Readout Principle for Solid-Contact Ion-Selective Electrodes. Anal. Chem. 2016, 88, 4369-4374. [CrossRef] [PubMed]

72. Lindner, E.; Gyurcs' $\alpha$ nyi, R.E. Quality Control Criteria for Solid-Contact, Solvent Polymeric Membrane Ion-Selective Electrodes. J. Solid State Electrochem. 2009, 13, 51-68. [CrossRef]

73. Bobacka, J. Conducting Polymer-Based Solid-State Ion-Selective Electrodes. Electroanalysis 2006, 18, 7-18. [CrossRef]

74. Lai, C.Z.; Fierke, M.A.; Stein, A.; Bühlmann, P. Ion-Selective Electrodes with Three-Dimensionally Ordered Macroporous Carbon as the Solid Contact. Anal. Chem. 2007, 79, 4621-4626. [CrossRef] [PubMed]

75. Crespo, G.A.; Macho, S.; Xavier Rius, F. Ion-Selective Electrodes Using Carbon Nanotubes as Ion-to-Electron Transducers. Anal. Chem. 2008, 80, 1316-1322. [CrossRef] [PubMed]

76. Hern’ $\alpha$ ndez, R.; Riu, J.; Bobacka, J.; Vallés, C.; Jiménez, P.; Benito, A.M.; Maser, W.K.; Xavier Rius, F. Reduced Graphene Oxide Films as Solid Transducers in Potentiometric All-Solid-State Ion-Selective Electrodes. J. Phys. Chem. C 2012, 116, 22570-22578. [CrossRef]

77. Crespo, G.A.; Macho, S.; Bobacka, J.; Xavier Rius, F. Transduction Mechanism of Carbon Nanotubes in Solid-Contact Ion-Selective Electrodes. Anal. Chem. 2009, 81, 676-681. [CrossRef] [PubMed]

78. Martinhon, P.T.; Carreño, J.; Sousa, C.R.; Barcia, O.E.; Mattos, O.R. Electrochemical impedance spectroscopy of lead(II) ion-selective solid-state membranes. Electrochim. Acta 2016, 51, 3022-3028. [CrossRef]

79. Vassilev, V.S.; Boycheva, S.V. Chemical Sensors with Chalcogenide Glassy Membranes. Talanta 2005, 67, 20-27. [CrossRef] [PubMed]

80. Schöning, M.J.; Kloock, J.P. About 20 Years of Silicon-Based Thin-Film Sensors with Chalcogenide Glass Materials for Heavy Metal Analysis: Technological Aspects of Fabrication and Miniaturization. Electroanalysis 2007, 19, 2029-3208. [CrossRef]

81. Vassilev, V.K.; Tomova, K.; Boycheva, S. Pb(II)-Ion-Selective Electrodes Based on Chalcogenide Glasses. J. Non-Cryst. Solids 2007, 353, 2779-2784. [CrossRef]

82. Mourzinaa, Y.; Schöning, M.J.; Schubert, J.; Zander, W.; Legin, A.V.; Vlasov, Y.G.; Kordos, P.; Lüth, H. A New Thin-Film Pb Microsensor Based on Chalcogenide Glasses. Sens. Actuators B Chem. 2000, 71, 13-18. [CrossRef]

83. Joachim, P.K.; Mourzina, Y.G.; Schubert, J.; Schöning, M.J. A First Step towards a Microfabricated Thin-Film Sensor Array on the Basis of Chalcogenide Glass Materials. Sensors 2002, 2, 356-365.

84. Moreno, T.V.; Malacarne, L.C.; Baesso, M.L.; Qu, W.; Dy, E.; Xie, Z.; Fahlman, J.; Shen, J.; Astrath, N.G.C. Potentiometric Sensors with Chalcogenide Glasses as Sensitive Membranes: A Short Review. J. Non-Cryst. Solids 2018, 495, 8-18. [CrossRef]

85. Bakker, E.; Bühlmann, P.; Pretsch, E. Carrier-Based Ion-Selective Electrodes and Bulk Optodes. 1. General Characteristics. Chem. Rev. 1997, 97, 3083-3132. [CrossRef] [PubMed]

86. Umezawa, Y.; Umezawa, K.; Sato, H. Selectivity Coefficients for Ion-Selective Electrodes: Recommended Methods for Reporting $K_{A, B}^{\text {pot }}$ Values. Pure Appl. Chem. 1995, 67, 507-518. [CrossRef] 
87. Molina-Holgado, T.; Pinilla-Macias, J.M.; Hernández-Hernández, L. Voltammetric Determination of Lead with a Chemically Modified Carbon Paste Electrode with Diphenylthiocarbazone. Anal. Chim. Acta 1995, 309, 117-122. [CrossRef]

88. Bates, R.G.; Dickson, A.G.; Gratzl, M.; Hrabeczy-Pall, A.; Lindner, E.; Pungor, E. Determination of Mean Activity Coefficient with Ion-Selective Electrodes. Anal. Chem. 1983, 55, 1275-1280. [CrossRef]

89. Radu, A.; Meir, A.J.; Bakker, E. Dynamic diffusion model for tracing the real-time potential response of polymeric membrane ion-selective electrodes. Anal. Chem. 2004, 76, 6402-6409. [CrossRef] [PubMed]

90. Zook, J.M.; Buck, R.P.; Langmaier, J.; Lindner, E. Mathematical Model of Current-Polarized Ionophore-Based Ion-Selective Membranes. J. Phys. Chem. 2008, 112, 2008-2015. [CrossRef] [PubMed]

91. Guzinski, M.; Lisak, G.; Sokalski, T.; Bobacka, J.; Ivaska, A.; Bochenska, M.; Lewenstam, A. Solid-Contact Ion-Selective Electrodes with Highly Selective Thioamide Derivatives of p-tert-Butylcalix[4]arene for the Determination of Lead(II) in Environmental Samples. Anal. Chem. 2013, 85, 1555-1561. [CrossRef] [PubMed]

92. Lisak, G.; Ciepiela, F.; Bobacka, J.; Sokalski, T.; Harju, L.; Lewenstam, A. Determination of Lead(II) in Groundwater Using Solid-State Lead(II) Selective Electrodes by Tuned Galvanostatic Polarization. Electroanalysis 2012, 25, 123-131. [CrossRef]

93. Toral, M.A.D.; Porter, A.; Schock, M.R. Detection and Evaluation of Elevated Lead Release from Service Lines: A Field Study. Environ. Sci. Technol. Lett. 2013, 47, 9300-9307. [CrossRef] [PubMed]

94. Hulsmann, A.D. Particulate Lead in Water Supplies. Water Environ. J. 1990, 4, 19-25. [CrossRef]

95. Triantafyllidou, S.; Parks, J.; Edwards, M. Lead Particles in Potable Water. J. Am. Water Works Assoc. 2007, 99, 107-117. [CrossRef]

96. Deshommes, E.; Laroche, L.; Nour, S.; Cartier, C.; Prévost, M. Source and Occurrence of Particulate Lead in Tap Water. Water Res. 2010, 44, 3734-3744. [CrossRef] [PubMed]

97. Clark, B.; Edwards, M. 3-D Lead Profiling to Characterize Particulate Lead Risks in Potable Water. In Proceedings of the AWWA Water Quality Technology Conference, Toronto, ON, Canada, 4-7 November 2012.

98. Abokifa, A.A.; Biswas, P. Modeling Soluble and Particulate Lead Release into Drinking Water from Full and Partially Replaced Lead Service Lines. Environ. Sci. Technol. 2017, 51, 3318-3326. [CrossRef] [PubMed]

(C) 2018 by the authors. Licensee MDPI, Basel, Switzerland. This article is an open access article distributed under the terms and conditions of the Creative Commons Attribution (CC BY) license (http:/ / creativecommons.org/licenses/by/4.0/). 